\title{
CORRENTES DA EDUCAÇÃO PARA OS MEDIA EM PORTUGAL: RETROSPECTIVA E HORIZONTES EM TEMPOS DE MUDANÇA
}

\author{
Manuel Pinto (*)
}

SÍNTESE: Ante a crescente complexidade dos fenômenos sociais e das opções sobre as quais devemos decidir, ante a avalancha informativa que os novos e os velhos meios de comunicação e informação põem à nossa disposição, ante as mensagens mais díspares que, de vários lados, tentam seduzir e convencer, resulta verdadeiramente urgente redefinir o conceito de cidadania, redescobrir os campos e as dimensões implicadas nele, ensaiar novos modos de aprender a viver, individual e coletivamente nos novos cenários que estão se desenhando, com a preocupação de reequilibrar o papel e a missão da escola.

Apesar de existir consenso de que uma prática democrática da cidadania encontra o perfeito campo para seu exercício na relação crítica com os meios, nos países que sofreram a experiência de regimes autoritários - e que possuem uma experiência democrática ainda insuficiente entretecida nas práticas cotidianas - resulta difícil conquistar um espaço para a educação para os meios.

Esse é o caso de Portugal, onde ainda se tem um conhecimento parcial e fragmentário das experiências realizadas neste campo. Ainda que tais experiências não constituíram verdadeiras políticas na matéria, existem sinais que estariam dando conta das mudanças e das inquietações que têm lugar, especialmente no âmbito das escolas e dos mestres e professores que lideram essas iniciativas.

Se entendemos a educação para os meios em sua relação com os processos socioculturais e de mudança social, devemos vinculá-la com as características mais notáveis dos mesmos: aceleração da vida social, enfatização da cultura do presente, deslocalização, alteração da noção de escala e crise das grandes narrativas que davam sentido à ação humana e à História.

Por outro lado, se a compreendemos como educação para a comunicação e para a cidadania, é necessário, antes de tudo, que se estabeleça um novo e adequado paradigma pedagógico que se apóie na relação entre a teoria e a prática, e que chegue aos centros de formação de professores.

(*) Professor associado do Departamento de Ciências da Comunicação e director do Curso de Mestrado em Comunicação, Cidadania e Educação do Instituto de Ciências Sociais da Universidade do Minho, Braga, Portugal. 


\begin{abstract}
SÍNTESIS: Ante la creciente complejidad de los fenómenos sociales y de las opciones sobre las que debemos decidir, ante la avalancha informativa que los nuevos y los viejos medios de comunicación e información ponen a nuestra disposición, ante los mensajes más dispares que, desde varios lados, intentan seducir y convencer, resulta verdaderamente urgente redefinir el concepto de ciudadanía, redescubrir los campos y las dimensiones implicados en él, ensayar nuevos modos de aprender a vivir, individual y colectivamente en los nuevos escenarios que se están diseñando, con la preocupación de re-equilibrar el papel y la misión de la escuela.
\end{abstract}

A pesar de que existe consenso en que una práctica democrática de la ciudadanía encuentra un perfecto campo para su ejercicio en la relación crítica con los medios, en los países que sufrieron la experiencia de regímenes autoritarios -y que poseen una experiencia democrática todavía insuficientemente entretejida en las prácticas cotidianas- resulta difícil conquistar un espacio para la educación para los medios.

Este es el caso de Portugal, donde aún se tiene un conocimiento parcial y fragmentario de las experiencias realizadas en este campo. Aunque dichas experiencias no constituyeron verdaderas políticas en la materia, existen señales que estarían dando cuenta de los cambios y de las inquietudes que tienen lugar, especialmente en el ámbito de las escuelas y de los maestros y profesores que lideran esas iniciativas.

Si entendemos a la educación para los medios en su relación con los procesos socioculturales y de cambio social, debemos vincularla con las características más notables de aquellos: aceleración de la vida social, enfatización de la cultura del presente, deslocalización, alteración de la noción de escala, y crisis de las grandes narrativas que daban sentido a la acción humana y a la Historia.

Por su parte, si la comprendemos como educación para la comunicación y la ciudadanía, es necesario, ante todo, que se establezca un nuevo y adecuado paradigma pedagógico que se apoye en la relación entre la teoría y la práctica, y que llegue a los centros de formación de profesores.

\title{
1. INTRODUÇÃO
}

A centralidade dos media no espaço público e na vida dos cidadãos converte-os numa instância que as sociedades deverão escrutinar com especial atenção. Pode mesmo dizer-se que a qualidade da vida individual e colectiva é, hoje, em grande medida, tributária da qualidade dos media. Por sua vez, a qualidade dos media é fruto de uma relação complexa, instável e frequentemente desigual com o conjunto dos cidadãos e dos grupos e instituições sociais. Daí que, a par de uma cultura de accountability permanente (McQuail, 1997), ou seja, de prestação de contas e de criação de canais de diálogo e interacção dos 
media com os seus públicos, torne-se necessário promover uma cultura de permanente e diversificado escrutínio público dos media.

Hoje é relativamente consensual que a formação pedagógica e cultural para uma relação crítica e esclarecida com os media e o campo mediático constitui uma das dimensões em que se traduz e promove a cidadania. Apesar de esta consensualidade se traduzir mais numa enunciação retórica do que numa praxis clara e assumida, em alguns meios ainda assim importa explorar as virtualidades desta perspectiva.

Em países como Portugal e outros do espaço ibero-americano que foram profundamente marcados por regimes autoritários e que possuem uma experiência democrática ainda insuficientemente entretecida nas práticas quotidianas, torna-se por vezes difícil conquistar espaços e horizontes para a chamada educação para os media. Uns porque olham os media como mero negócio, outros porque possuem deles uma concepção instrumental (e instrumentalizadora), ambos acabam por ter dificuldade em os assumir como instâncias decisivas de produção simbólica, que não podem, sob pena de graves enviesamentos, ser cindidos dos terrenos da cultura e das práticas culturais.

A experiência portuguesa revela como aquilo que tem sido uma conquista e um percurso consolidado em vários países - a educação para os media - redunda em experiências fragmentárias, inconsequentes, incapazes de se articular numa plataforma de acção política e educativa. Mas nem por isso pouco importantes, em particular para aqueles que nelas estiveram ou se encontram directamente envolvidos. Essa é a constatação que podemos fazer, quase 30 anos depois da Revolução dos Cravos de 25 de Abril de 1974, que pôs fim a cerca de meio século de ditadura, repressão e censura.

Uma das formas de compreender os porquês de a generosidade dos esforços de lançar e consolidar a educação para os media é procurar reconstituir os "fios» através dos quais se foram exprimindo e tecendo as experiências realizadas ao longo das últimas décadas. É tentar caracterizar as origens, orientações, potencialidades e fraquezas desses "fios», tendo em consideração os contextos socioculturais e políticos do seu desabrochar e do seu evoluir.

Devemos esclarecer, desde o início, que não propugnamos uma filosofia de unicidade na orientação da educação para os media. É, a nosso ver, salutar e vantajoso que a pluralidade da vida social, em ter- 
mos de posicionamentos e mundividências, tenha tradução na diversidade das experiências e iniciativas neste terreno. Somos, assim, a favor de um ecumenismo que assenta no valor e no reconhecimento da diversidade, e que se constrói do debate entre as diferentes orientações.

Neste texto, pretendemos propor alguns contributos para repensar o caminho que tem sido trilhado a este nível na Europa e particularmente em Portugal na última década, tendo presente o contexto de aceleradas e profundas mudanças a que vimos assistindo nos anos mais recentes, em especial no que respeita à emergência e difusão das chamadas novas tecnologias de informação e comunicação.

Para tal, propomos uma reflexão em três tempos. No primeiro, procuramos pôr em evidência algumas das tendências da educação para os media em Portugal nas últimas décadas; no segundo, iremos fazer alusão a certas mudanças significativas no panorama mediático e comunicacional e às respectivas incidências no campo educacional; no terceiro, apresentaremos algumas linhas que, a nosso ver, merecem ser consideradas no futuro.

\section{RETROSPECTIVA CRÍTICA DA EDUCAÇÃO PARA OS MEDIA EM PORTUGAL}

Uma primeira nota que a fazer é que não foi empreendido ainda um levantamento e um estudo rigoroso sobre o que tem sido feito entre nós num campo que, em termos muito genéricos, poderíamos designar como de interacção entre a comunicação e os media, por um lado, e a educação e a escola, por outro. 0 que conhecemos é parcelar e fragmentário. Por essa razão, tal estudo começa a ser necessário para apurar a nossa consciência crítica acerca de um passado que está longe, como é bom de ver, de se confinar às experiências, iniciativas e projectos em que cada qual esteve ou está envolvido.

\subsection{TRADIÇÕES E ORIENTAÇÕES}

Considerando a informação disponível, iremos propor um quadro que compreende seis orientações na história recente das práticas de educação para os media em Portugal: o cinema na escola; a imprensa escolar; as tecnologias educativas; actualidade e educação para a cidadania; estudo da comunicação e dos media; e a educação para os media 
propriamente dita. Vejamos, de forma sumária, os traços caracterizadores de cada uma destas orientações ou tradições.

\section{O cinema e a escola ou educação cinematográfica}

O cinema começou por ser considerado pelas elites culturais um produto culturalmente desqualificado, mas alguns realizadores das primeiras décadas do século xx fizeram dele a «sétima arte». E a instituição escolar foi-se apercebendo do potencial educativo desta nova forma de expressão artística, embora fosse mais fácil levar a escola ao cinema do que levar o cinema à escola. Importa, porém, não esquecer que eram professores muitos dos animadores e frequentadores do movimento cineclubista (Monteiro, 2000).

Em Portugal têm sido desenvolvidas várias experiências que procuram abordar o cinema em contexto escolar. Têm tido por objectivos suscitar entre os alunos o gosto pelo cinema, promover uma iniciação à linguagem e estética cinematográficas, apoiar e enriquecer o debate de temas de actualidade ou a leccionação de determinadas matérias, como a História, a Antropologia, as línguas estrangeiras, a formação sociomoral, etc. Um trabalho relevante e continuado neste registo foi desenvolvido a partir dos anos 70 pelo Dr. Vieira Marques, nome principal do Festival de Cinema da Figueira da Foz, de que foram publicados alguns materiais ${ }^{1}$.

Não se pense que a interacção entre o cinema e a escola é algo do passado. Um trabalho recente ${ }^{2}$ dava conta de relatos de experiências de orientação diversa desenvolvidas em várias escolas já nos anos 90 . E um sinal revelador de que há muitas instituições educativas que continuam a ter com ele uma relação estreita está em que, num levantamento feito em 1993 pela Associação para a Educação Pluridimensional e a Escola Cultural, permitiu apurar que, num total de cerca de 400 clubes escolares de algum modo ligados à comunicação, ao jor-

10 extinto FAOJ (Fundo de Apoio aos Organismos Juvenis) publicou, nos anos 70, um trabalho de Vieira Marques intitulado A linguagem cinematográfica, de que foram publicados mais recentemente alguns excertos em M. Pinto e A. Santos (1995), O cinema e a escola: guia do professor, Público na Escola, núm. 6, Lisboa, Público Comunicação Social, pp. 98-100.

2 Casos das escolas secundárias de Esmoriz e de Gondomar e da EB 2-3 de Aldoar (Porto), por exemplo. Veja-se os relatos apresentados em M. Pinto e A. Santos, op. cit., pp. 95-97. 
nalismo e aos media, havia 23 ligados especificamente ao cinema, um igual número de clubes ao vídeo, e 16 ao cinevídeo³.

0 académico que continua a trabalhar nesta linha propondo uma «pedagogia da comunicação» tendo como referencial o património e a obra cinematográfica, é Vítor Reia-Baptista, docente da Universidade do Algarve. Vários trabalhos publicados ao longo dos últimos anos (v. g. 1995), e já em 2003, a sua tese de doutoramento, intitulada «A dimensão pedagógica dos media na pedagogia da comunicação: o caso do cinema e das linguagens fílmicas».

\section{Imprensa escolar e jornalismo escolar}

Apesar de insuficientemente estudada ${ }^{4}$, esta será talvez a tradição com mais significado e mais implantação nas escolas portuguesas. À medida que os processos de composição e de impressão se foram tornando mais acessíveis - e mesmo antes - muitos estabelecimentos de ensino lançaram-se na produção de jornais escolares. 0 espírito inovador inspirado nas ideias e propostas de Freinet e do Movimento da Escola Moderna deu um importante contributo nesse sentido, mas o jornalismo escolar extravasa essa orientação.

De acordo com dados de um estudo nacional relativamente recente ${ }^{5}$, que incidiu sobre uma amostra de mais de um milhar de escolas do ensino não superior (com excepção do $1 .^{\circ}$ ciclo do ensino básico), mais de 50 por cento editavam algum tipo de jornal.

É certo que por debaixo do chapéu chamado imprensa escolar podemos encontrar uma multiplicidade de práticas e de atitudes. Em texto anterior 6 referimo-nos a quatro modelos de jornal escolar - 0 jornalarquivo, o jornal institucional, o jornal «tecno» e o jornal informativo ${ }^{7}$

3 Cf. Boletim da AEPEC, núm. 18, Março-Outubro de 1993.

4 Encontra-se em desenvolvimento, no âmbito do mestrado de Ciências da Comunicação na Universidade do Minho, aquela que deverá ser uma das primeiras investigações académicas sobre o jornalismo escolar, levada a cabo por João Carlos Gonçalves.

5 Ausenda Vieira e Teresa Fonseca (1996), Os jornais escolares e o desenvolvimento de novas dinâmicas educativas, Lisboa, Instituto de Inovação Educacional.

6 Cf. Manuel Pinto (1997) «Objectivos e modelos de jornal escolar», in Público na escola, núm. 76, Novembro.

7 Segundo esta tipologia, o jornal-arquivo constitui um repositório do que foi feito, com o fim de recordar; o jornal institucional assume-se como porta-voz oficial da escola, controlado em maior ou menor grau pela respectiva direcção; o jornal «tecno» 
precisamente para dar conta de distintas concepções e orientações. Em todo o caso, é possível detectar em todas elas a preocupação de dar a conhecer, de comunicar. E, se é verdade que, apesar de tudo, não é muito frequente que a experiência de produção de jornais escolares seja assumida como dimensão de um projecto mais amplo de educação para os media, não é menos verdade que tal experiência constituirá, muitas vezes, uma forma rica e fecunda de os alunos experimentarem algumas das questões e desafios próximos daqueles que enfrentam os profissionais dos grandes meios de comunicação.

\section{Abordagens a partir da relação tecnologia-educação}

No âmbito das ciências da educação foi ganhando forma, sobretudo a partir dos anos 60 , uma preocupação crescente pelo desenvolvimento, aplicação e avaliação de sistemas, técnicas e meios para melhorar a aprendizagem, identificados com a «tecnologia educativa», e, num registo mais restritivo que era então usual, com meios audiovisuais de ensino (Hendry, in Abrantes, 1981, p. 522).

Hoje, os horizontes deste campo específico das ciências da educação são bastantes mais largos. Alguns autores, por exemplo, tendem a adoptar designações como comunicação educacional, comunicação multimédia ou comunicação mediada por computador. Neste contexto é revelador o facto que, nas instituições de formação de docentes, esta componente passou a ser consagrada nos curricula e na investigação, não raro associada ou enquadrada na área do desenvolvimento curricular, estando hoje consagrada no campo académico, e, em especial, nos cursos de formação de professores (Ponte, 2000).

Não é assim de estranhar que tal movimento tenha induzido nas escolas, pela via da introdução e do uso das modernas tecnologias de informação e comunicação - desde o retroprojector e o projector de slides ou o vídeo até o computador multimedia ligado a redes telemáticas - uma atenção aos problemas da comunicação e dos meios de difusão colectiva.

De facto, em muitos casos algumas das pessoas e instituições ligadas hoje à educação para os media tiveram uma trajectória cuja origem radica na tecnologia educativa, ou, mais rigorosamente, no estudo

procura sobretudo cuidar do grafismo e da apresentação, tirando partido de recursos tecnológicos; finalmente, o jornal informativo é aquele que procura alimentar a comunicação na escola, assumindo um papel activo, interventivo e crítico no seu quotidiano. 
e na aplicação das interacções entre tecnologia e educação. A partir da problematização do papel social e cultural das tecnologias e da análise das modalidades de acesso, uso e incorporação, bem como dos contextos económico-políticos da sua produção e difusão, introduziu-se uma vertente importante no campo educativo, imprescindível à abordagem ecuménica da educação para os media que preconizamos.

\section{Actualidade e educação para a cidadania}

Não se pode dizer que esta perspectiva de abordagem constitua uma tendência muito saliente, mas existe e reveste alguma especificidade. Procura sublinhar o papel que os media assumem como instâncias de enunciação, construção e significação dos eventos e situações que marcam o que em cada momento se passa no mundo próximo e distante. A informação jornalística constitui, nesta perspectiva, um precioso contributo à educação escolar, enquanto factor de motivação, de ilustração e até de actualização (dos manuais) - ou seja, como recurso pedagógico - e enquanto texto a ser acolhido, analisado e interpretado. Deste ponto de vista, a imprensa, e em geral os media, constituiriam um apoio insubstituível a processos de ensino-aprendizagem que tomam a compreensão e significação do mundo e a formação para uma cidadania consciente e participativa como objectivos seus.

De entre os exemplos que poderiam ser apresentados desta perspectiva, poderíamos destacar o Projecto CIMA (Compreender e Intervir no Mundo Actual), da Escola Superior de Educação de Setúbal, que ao longo de vários anos dinamizou a acção de um bom número de escolas. Mais relevante ainda é o trabalho do Projecto «Público na Escola», que, desde o seu início em 1989, colocou a relação com a actualidade como seu objectivo primeiro ${ }^{8}$, e que, tendo por base de

8 De entre os objectivos do Projecto, destacam-se:

«a) contribuir para uma relação mais próxima entre a actualidade e a escola;

b) estimular nos jovens estudantes a consciência dos seus direitos e possibilidades de acção face à comunicação social, ajudando-os, nomeadamente, a decodificar a linguagem da imprensa;

c) promover entre os jovens uma visão mais dinâmica e mais interessante da vida social, criando condições para melhor se situarem nas grandes questões que atravessam a sociedade contemporânea;

d) contribuir para o desenvolvimento do espírito crítico das novas gerações, nomeadamente face à comunicação social».

(Cf. Manuel Pinto (1991), A imprensa na escola-guia do professor, Lisboa, Público Comunicação Social, p. 44; Público, Livro de Estilo, Lisboa, Público Comunicação Social, 1998, p. 390). 
trabalho um jornal diário de referência, tem continuado a incentivar das mais diversas formas uma relação da educação com o jornalismo e a actualidade.

\section{Estudo da comunicação e dos media}

Depois do período revolucionário iniciado em 25 de Abril de 1974 , os objectivos do sistema educativo, e sobretudo os planos curriculares, passaram a dar algum acolhimento aos novos fenómenos sociais, e em particular aos media. Se essa abertura cabia em algumas disciplinas e áreas disciplinares (nomeadamente relacionadas com as línguas e os estudos sociais), viria a ter também consagração através da criação de disciplinas e de cursos específicos no ensino secundário. Assim, por exemplo, na oferta proporcionada por um bom número de escolas secundárias, vigorou durante cerca de dez anos a disciplina de Iniciação ao Jornalismo, que constituiu uma forma de promover a abordagem do campo mediático no sistema escolar, e de levar alguns jornalistas à escola na qualidade de docentes dessa matéria.

Com a entrada em vigor da reforma educativa dos finais dos anos 80 , passou a existir um curso tecnológico de comunicação, o qual registou uma significativa procura, a ponto de chegar a existir perto de duas centenas de instituições educativas que o ofereciam.

Como é evidente, o estudo dos media não equivale a educação para os media, como um debate já antigo no Reino Unido, sublinhou. Mas pode ser - e em alguns casos tem sido - um excelente incentivo nesse sentido, além de que nos programas da disciplina de Comunicação e Difusão está expressamente previsto um módulo sobre Educação para os Media.

\section{A educação para os media como dimensão transversal do currículo}

Nenhuma das orientações apresentadas esgota o que se entende hoje em dia por educação para os media, porém qualquer uma delas constitui uma dimensão e pode dar um contributo importante nesse sentido.

A educação para os media não se reduz à introdução e à utilização das novas tecnologias da informação e comunicação na escola; 
não se pode circunscrever ao estudo dos media nem à produção de jornais. Considera quer a dimensão da análise (leitura crítica) quer a da produção, procurando desenvolver uma perspectiva holística que entende os media não apenas como conteúdos ou mensagens, mas também como indústrias e serviços político-económica e socioculturalmente situados, e como propostas diferencialmente apropriadas e significadas ao nível das práticas sociais e dos contextos de recepção. Além disso, a educação para os media procura promover a tomada de consciência dos modos socioculturalmente distintos de comunicar, de desenvolver competências de expressão e de comunicação de todos, em ordem a uma participação activa e esclarecida na vida local e social.

Neste sentido, a educação para os media (ou educação para a comunicação, ou, ainda, pedagogia da comunicação) constitui uma proposta articulável com as práticas pedagógicas na sala de aula e nas actividades escolares em geral, mas também com óbvias incidências nas políticas de educação e nas práticas culturais. E, tal como o sistema social em que se inscreve, constitui - ou deve constituir - uma realidade plural nas suas formas de concretização.

\subsection{SINAIS DE MUDANÇA E DE INQUIETAÇÃO}

Apesar da tendência para desconsiderarmos o que fazemos, muito por falta de uma dimensão comparativa com o que se passa noutros países, importa sublinhar que na última década alguma coisa se fez em Portugal para conferir à educação para os media uma consistência e uma visibilidade mais acentuadas. 0 aspecto mais saliente consiste na multiplicação de iniciativas e de projectos ao nível das escolas. Uma delas, como a Semana dos Media, começou por ser uma iniciativa do projecto «Público na Escola» no início da década de 90, e passou depois a ser organizada anualmente pelo Instituto de Inovação Educacional enquanto este existiu ${ }^{9}$, permitiendo identificar e em alguns casos pôr em ligação projectos de muitas dezenas, se não centenas de escolas ${ }^{10}$. Outro sinal deste dinamismo reside na quantidade, diversidade e quali-

9 O Instituto de Inovação Educacional, um departamento dos serviços centrais do Ministério da Educação, foi extinto com a chegada ao poder, em 2002, do XV governo constitucional, de centro-direita, no quadro de um vasto conjunto de medidas de contenção dos gastos públicos.

10 Cf., por ex. Ausenda Vieira e Rosália Vargas (1996): Rede de projectos de educação e media, catálogo 1995-1996. Col. «Aprender com os media», núm. 4, Lisboa, Instituto de Inovação Educacional. 
dade dos concursos nacionais de jornais escolares e de projectos de utilização dos media na escola, promovidos desde 1990 pelo projecto «Público na Escola», com o apoio do Ministério da Educação. Apesar disto, não podemos deixar de considerar que se trata ainda de uma dinâmica de reduzida expressão no sistema educativo, que remete para preocupações igualmente minoritárias no âmbito dos docentes e dirigentes das instituições e dos serviços oficiais.

Relevante foi, neste contexto, a constituição em 1997 da Associação Educação e Media (AEM), que realizou, nos finais dos anos 90, encontros anuais de docentes, promoveu formação específica e trouxe ao país alguns nomes relevantes da área da educação para os media no panorama internacional. Esta dinâmica associativa surgiu na cidade galega da Corunha, quando num encontro internacional ali realizado em 1995, as cerca de duas dezenas de docentes portugueses presentes consideraram ter chegado a hora de instituir uma associação. Um grupo ligado à Escola Superior de Educação de Setúbal teve nesse processo um papel dinamizador importante.

Duas vertentes que começam a adquirir expressão, embora ainda sem a amplitude desejável, são a da formação e a da investigação. A este nível destaca-se, por um lado, os trabalhos desenvolvidos pela Escola Superior de Educação da Universidade do Algarve e pelo Instituto de Estudos da Criança (IEC) da Universidade do Minho, instituições em que a educação para os media constitui matéria obrigatória na formação inicial. No caso da formação especializada, o IEC passou a promover também, desde 1995, cursos de estudos superiores especializados em educação para a comunicação social, em regime pós-laboral e com a duração de dois anos, destinados a educadores de infância e professores do $1 .^{\circ}$ ciclo do ensino básico. Por outro lado, quer nestas escolas, quer noutras, a educação para os media e matérias afins têm vindo a ser adoptadas como temas de teses de mestrado e doutoramento. Nos últimos dez anos foram apresentadas cerca de uma dezena em provas públicas, sendo previsível que essa tendência venha a continuar ou mesmo a crescer nos anos mais próximos.

O facto mais relevante em época recente foi a decisão da Universidade do Minho de criar o primeiro mestrado com a especialização em Comunicação, Cidadania e Educação ${ }^{11}$. Os seus objectivos, na linha

11 Uma apresentação online do enquadramento, objectivos e estrutura curricular deste curso pode ser consultada em <http://www.ics.uminho.pt/dcc/cur/mestrados/com_cid_edu/mestr_com_cid_edu_1.htm $>$. 
de uma diversificada experiência desenvolvida num grande número de países e estimulada por diversas organizações internacionais como a UNESCO ou o Conselho da Europa, inscrevem-se no entendimento de que o exercício da cidadania exige e supõe a educação para os media ou, talvez melhor ainda, a educação para a comunicação. Não apenas ou necessariamente orientada para a formação de consumidores mais críticos, mas também de pessoas capazes de produzirem informação e de comunicarem com os seus semelhantes de modo eficiente e significativo. O Curso foi implementado pela primeira vez em 2002-2003, e tem vindo a estabelecer contactos com outras experiências de pós-graduação em Educação para os Media, em especial com as da Universidade Autónoma de Barcelona.

Uma outra faceta dos estímulos ao desenvolvimento da educação para os media provém dos próprios meios de comunicação social, ou pelo menos de alguns deles. Além do já referido «Projecto Público na Escola», a funcionar desde 1990, merece especial referência o trabalho desenvolvido a partir do sector de Programas Infantis e Juvenis do operador público de televisão RTP, nomeadamente na concepção e produção de programas de cunho educativo de grande sucesso entre os segmentos etários mais novos, como foi o caso da co-produção «Rua Sésamo» e da produção "Jardim da Celeste». Foi uma experiência de grande alcance educativo e cultural que marcou toda uma geração de crianças e a que, infelizmente, os responsáveis do canal não foram capazes de dar continuidade. Mas importa não esquecer um grande número de jornais e de rádios locais que têm apoiado ou promovido, em conjunto com as escolas, iniciativas de grande mérito na ligação entre a educação e os media.

O Ministério da Educação tem sido, neste contexto, uma instância que se tem destacado mais pelo apoio e viabilização do que propriamente pela promoção de iniciativas. Várias das dinâmicas já referidas contaram com o seu apoio, em especial através do entretanto extinto Instituto de Inovação Educacional. (A título de exemplo, o concurso anual «Educar inovando, inovar educando» contemplava a educação para os media entre as suas prioridades). 0 mesmo Instituto, por outro lado, lançou em 1994 uma colecção intitulada «Aprender com os media», de que foram publicados alguns volumes até ao presente.

É preciso dizer que nunca chegou a haver, pelo menos de uma forma explícita, uma estratégia articulada neste domínio. A então Secretaria de Estado do Ensino Básico e Secundário encomendou à Universi- 
dade do Minho, em 1993, um estudo que poderia ter estado na base de uma estratégia desse tipo ${ }^{12}$, mas as propostas nele contidas foram esquecidas com as mudanças de ministros e secretários de Estado. A educação para os media foi, ao longo dos anos 90, um fio de água débil mas que foi correndo, com apoio do Estado, embora sem nunca ter chegado a constituir uma prioridade das políticas educativas. Com a mudança de orientação política recente, e com a onda de cortes e de medidas de contenção orçamentais num quadro económico marcado pela recessão, os tempos não têm ido favoráveis para as políticas de educação para os media, deixando-se assim subentender que pouco mais serão do que flores para enfeitar discursos de ocasião.

As experiências em que temos estado envolvidos há mais de uma década no plano da formação, da investigação e da intervenção, levam-nos a propor algumas reflexões que pesquisas futuras mais sistemáticas poderão desenvolver e aprofundar, ajudando a confirmar ou infirmar o que aqui sugerimos. Assim:

1. De um modo geral, o clima de recusa (ou mesmo de hostilidade) relativamente aos media, e, em especial, à possibilidade/necessidade da sua abordagem na instituição escolar, parece ter-se vindo a diluir, mesmo tendo em conta a crescente comercialização que se regista numa boa parte da oferta mediática.

2. Grande parte do corpo docente não considera, contudo, que tal abordagem constitua uma preocupação premente ou uma prioridade da acção educativa escolar. Se tal preocupação existe para alguns, a falta de condições subjectivas (competências, capacitação, formação) e objectivas (equipamento, apoio institucional, governamental) poderá ser razão para a falta de iniciativa.

3. As experiências e projectos levados a cabo designadamente desde o início dos anos 90 configuram um quadro de iniciativa que tem vindo a crescer e a afirmar-se, embora constitua preocupação minoritária; de resto, muitas dessas iniciativas, apesar de lidarem com os media ou de os terem

12 M. Pinto, A. Baleiras, A. Santos e S. Pereira (1994): Escola e comunicação social: desafios e propostas de acção. Braga, CEFOPE da Universidade do Minho (polic.). 
como tema central, não incorporam uma reflexão mais ampla e aprofundada do papel dos media na sociedade e na vida das crianças e dos adolescentes.

4. Existe um défice assinalável de reflexão e de problematização do trabalho levado a cabo no terreno, directa ou indirectamente referenciável ao movimento da educação para os media. As motivações, pressupostos, referenciais teóricos, problemas metodológicos, discussão e análise comparativa de resultados, réplica de experiências e avaliação, constituem vertentes pouco consideradas até ao presente em Portugal.

5. As influências e os efeitos dos media (percepcionados como negativos) parecem ser uma preocupação subjacente a muitos discursos e práticas a avaliar por sinais de variada origem. 0 peso desta perspectiva parece ser bem mais saliente e marcante do que aquel outro que considera as práticas sociais, os processos e os contextos de recepção e de atribuição de sentido.

6. Na mesma linha, parece ter-se vindo a afirmar e fortalecer, nas práticas e nos discursos educativos, uma orientação de forte pendor técnico e modernizador, que é marcante no terreno da formação de professores e educadores, com inevitável impacte nas concepções e enquadramentos da educação para os media13. A saliência e alcance político-educacional deste ponto exige que nos detenhamos um pouco mais sobre ele.

\section{A «DERIVA TECNOCÊNTRICA» DA EDUCAÇÃO PARA OS MEDIA}

Uma das grandes derivas que enfrenta a educação para os media em vários países, Portugal incluído, é o da sua redução ao factor técnico, ou, pelo menos, a adopção de uma abordagem "tecnocêntrica» para enunciar e ter em conta processos que são antes de mais sociais.

13 Um estudo recente intitulado $A$ educação para os media e a formação inicial de professores, realizado como dissertação de mestrado no ISCTE por Rui Coelho, indica que cerca de 70 por cento das instituições de formação inicial inquiridas relacionam a educação para os media com disciplinas e actividades de orientação marcadamente tecnológica. 
Um tal tecnocentrismo (expressão de modalidades de acção e de concepções referenciáveis ao "determinismo tecnológico») resvala facilmente para formas mais ou menos dissimuladas de tecnocracia. Ora a tecnocracia é, por sua vez, uma forma de dissimulação do poder e dos interesses de quem controla a técnica e a produção tecnológica.

Em rigor, a deriva não é nova. Conhecíamo-la quando alguns consideravam que, para dar vida a experiências de formação de telespectadores críticos, tornava-se imprescindível ter um televisor na sala de aula. Ou quando se fazia equivaler a educação para os media ao uso de equipamentos e materiais diversos, fossem eles máquinas de projectar diapositivos, acetatos, videogramas, ou, mais recentemente, apresentações em powerpoint.

Com a divulgação da Internet e a pressão para a sua difusão pelas escolas, foram investidas somas avultadas e lançados programas oficiais e privados no sentido de tornar o acesso o mais universal possível e de incentivar o uso frequente da rede. No quadro de um discurso geral de modernização e inovação das escolas e do ensino-aprendizagem, tornou-se corrente a ideia de que a exclusão do acesso e da eficiente utilização da Internet é sinónimo de exclusão social e cultural.

Em boa medida, assim é. Contudo, convém sublinhar que é bem mais fácil enveredar por discursos e práticas que, consciente ou inconscientemente, alimentam e ampliam novos mitos como o da comunicação automática e universal, do que se interrogar sobre o que significa entrar - como leitor ou escritor - no grande ciber-oceano informativo. Ou seja: sobre o que significa em verdade «navegar» na Internet.

Acresce que algumas das iniciativas e dos projectos dos últimos anos, norteados por esta orientação tecnocêntrica, inscreveram nos seus objectivos a educação para os media ou a «alfabetização digital». Se a implantação e o uso de tecnologias de informação e comunicação trouxessem consigo a educação para os media como que por decorrência inevitável, não teríamos neste momento motivos de preocupação.

Não se está a sugerir que a educação para os media possa ou sequer deva prescindir das tecnologias, novas ou velhas. Pelo contrário, a dimensão tecnológica deve constituir uma das suas dimensões fundamentais, já como ferramenta que configura e veicula as mensagens ou que abre a possibilidade da produção própria, já como fenómeno sociocultural, político e económico. As tecnologias estão longe de 
ser um mero problema técnico. São ferramentas ao serviço do ensino e da aprendizagem, mas são igualmente produto das relações sociais, expressão de um certo mundo, e contribuem ao mesmo tempo com a sua quota-parte para a configuração desse mesmo mundo (cf. Tedesco, s/d).

Há toda uma história da relação entre as tecnologias e as sociedades, cujo estudo muito beneficiaria certos movimentos e opções no tempo presente. Essa história, em muitos dos seus momentos, tem balanceado entre os extremos demarcados, de um lado, pelo fascínio e crença nos poderes demiúrgicos das técnicas, e, do outro, pela suspeita, pelo medo e até mesmo pelo pavor da técnica. Esta corrente tecnófoba remonta pelo menos a Platão, que nos fala, no Fedro, do empobrecimento que a invenção da escrita representaria (representou) para os humanos, ao deslocar para fora das pessoas um saber/sabedoria que, até então, era cultivado dentro através da memória. Por vezes exprime-se por meio da contraposição e hierarquização de tecnologias. Assim, por exemplo, Neil Postman, em Amusing Ourselves to Death ou em The Disappearance of Childhood, sustenta que a televisão (repare-se: não certos programas ou certos conteúdos, mas a TV tout court) veio trazer uma enorme perda cultural, ilustrando aquilo que o mesmo autor viria a caracterizar, anos mais tarde, como a rendição da cultura à tecnologia (Postman, 1994).

Há, nas orientações mais encantadas como nas mais reticentes às tecnologias, uma matriz comum de forte pendor determinista. Ambas assentam na pressuposição de que a difusão e o uso produzem, de forma mais ou menos automática, determinados efeitos, sejam eles positivos ou negativos. E este determinismo está presente, de modo por vezes subliminar, como marca forte dos programas que visam difundir as novas tecnologias de informação e comunicação (NTIC) na escola, e, mediante essa via, promover a inovação na educação.

No terreno educativo, porém, dir-se-ia que a imagem das NTIC está associada a uma carga predominantemente positiva, como se nestas tecnologias residisse a redenção da escola e da educação escolar perante a sociedade. A interactividade, a auto-aprendizagem, a pesquisa autónoma, a interdisciplinaridade, seriam resultados «naturais» esperáveis do "extraordinário poder» atribuído às novas tecnologias, que grandes grupos multinacionais, sequiosos de aumentar os seus lucros e a sua quota de mercado, não se cansam de agitar e propagandear.

Neste quadro, e no sentido de abrir caminho e espaço à educação para os media, é fundamental interrogar as concepções e propos- 
tas instrumentalistas, modernizantes e tecnocráticas que parecem conquistar hoje os discursos e as orientações de vários sectores-chave da União Europeia e de diversos ministérios da Educação, e procurar enfatizar o lugar dos sujeitos e os grupos que interagem com a mediação das tecnologias, tendo em conta os seus respectivos contextos de vida. Trata-se de acentuar orientações de pendor pedagógico e cultural, dirigidas para o exercício de uma cidadania esclarecida e participada, em que o recurso às tecnologias e a compreensão do seu lugar na vida social habilitem cada vez mais as pessoas e os grupos a uma vida mais autónoma, mais significativa e mais feliz. Há que passar pelas tecnologias, mas para visar mais largo e mais longe: as lógicas e os interesses de que emergem, as tendências que nelas se detectam, as linguagens e os formatos a que recorrem, os usos sociais e formas de apropriação a que dão lugar. 0 acesso às tecnologias e a mais e melhor informação pode ser condição necessária, mas não suficiente na formação dos cidadãos nas sociedades dos nossos dias. Como observou Dominique Wolton, «nada há de mais perigoso do que ver na presença de técnicas cada vez mais performativas a condição da aproximação entre os homens» ${ }^{14}$. $\mathrm{E}$ Paul Virilio foi ainda mais longe: "Detesto a idolatria. A Internet não é mais do que um instrumento. Ora não se pode esperar que a salvação venha de um objecto» ${ }^{15}$.

A educação para os media deve ter o seu centro de gravidade não tanto nos media e nas tecnologias, mas na comunicação e nos processos e competências nela implicados. É o desenvolvimento de competências e de práticas comunicativas ao âmbito individual e grupal, e a promoção de uma cultura de comunicação na escola, na família, no movimento ou associação local, que deveria ser procurado e promovido com a educação para os media. Como temos sublinhado noutras ocasiões ${ }^{16}$, constitui um contra-senso despender vastas somas de tempo, dinheiro e energia em grandes programas de fornecimento de tecnologias de comunicação e informação, sem uma percepção

14 Dominique Wolton (1999): Internet et après? Une théorie critique des nouveaux médias, París, Flammarion, p. 11.

15 Gavi, Philippe (1996): Entrevista a Paul Virilio, Le nouvel observateur, hors série La soif de Dieu, voyage au coeur des religions, Novembro.

16 Retomo aqui algumas ideias expressas em dois textos recentes: «Os filhos dos media e os conflitos com a escola», in VV.AA (2000): As pessoas que moram nos alunos: ser jovem hoje na sociedade portuguesa, Porto, Edições Asa; e «A formação para o exercício da cidadania numa sociedade mediatizada», in Presidência da República (2000): Os cidadãos e a sociedade da informação, Lisboa, Imprensa Nacional-Casa da Moeda. 
clara de que tais equipamentos e redes são da ordem dos meios e não das finalidades.

Perante a complexidade crescente dos fenómenos sociais e das opções que somos chamados a assumir; perante a avalanche informativa que os novos e velhos meios de comunicação e informação disponibilizam; perante as mensagens mais díspares que de vários lados procuram seduzir e convencer - torna-se urgente redefinir o conceito de cidadania, redescobrir os campos e as dimensões nele implicados, ensaiar novos modos de aprender a viver individual e colectivamente nos novos cenários que se estão a desenhar, com a preocupação de reequacionar o papel e a missão da escola (Pinto, 2003).

\section{HORIZONTES DA EDUCAÇÃO PARA OS MEDIA NUM NOVO QUADRO SOCIOCULTURÁL E MEDIÁTICO}

Se entendermos os media como agências centrais de produção simbólica das sociedades contemporâneas, não poderemos deixar de compreender a educação para os media como intimamente relacionada com os processos socioculturais e com a mudança social.

Estes processos podem ser caracterizados por um conjunto de traços, dos quais destacamos os seguintes:

1. A aceleração da vida social, bem como da frequência das inovações, das descobertas, dos ritmos de vida, das possibilidades de contactos e de trocas de informação.

2. Enfatização da cultura do presente, do «aqui e agora», perante um futuro tornado ora perigoso e incerto e perante um passado confundido com 0 «reino do esquecimento».

3. Separação espaço-tempo, ou, na expressão do sociólogo Anthony Giddens ${ }^{17}$, des-localização: diversificação de espaços; raios de acção/circulação cada vez mais alargados.

4. Alteração da noção de escala em que nos situamos e nos referenciamos por relação com os outros: entre o infinitaPress.

17 Giddens, A. (1990): The Consequences of Modernity, Cambridge, Polity 
mente grande dos espaços siderais e o infinitamente pequeno das unidades mais elementares da matéria, passando pelo infinitamente complexo da análise dos fenómenos.

5. Crise das grandes narrativas que davam sentido à acção humana e à História, e afirmação hegemónica da economia de mercado e da ideologia neoliberal.

Alguns dos fenómenos apontados podem ser analisados no campo mediático, campo em que as transformações dos anos 80 e 90 se revelaram de uma profundidade e alcance consideráveis. Para um país como Portugal, é necessário recuar um pouco mais e chamar a atenção para esses anos 70 que trouxeram o fim da ditadura e das guerras coloniais, as liberdades e direitos fundamentais, o re-encontro com a Europa, a aprendizagem da vida democrática e o percorrer de um caminho de efectivação da participação que outros tinham já calcorreado.

Para o bem e para o mal, Portugal começou a acertar o passo com as sociedades ocidentais desenvolvidas, pondo em acção, no domínio das políticas de comunicação e media, processos marcados por: liberalização e desregulamentação expressa, nomeadamente na acção legislativa que retira o Estado de um papel hegemónico, e, no caso da TV, monopolista; integração e concentração, definida como «toda a forma mais ou menos avançada de combinação de poder e de propriedade sobre as actividades de uma sociedade ou de um grupo de sociedades» ${ }^{18}$; internacionalização e globalização, decorrente no caso português em especial, da integração no espaço da comunidade europeia, mas como fenómeno praticamente de um só sentido (capitais estrangeiros que entram em empresas e grupos nacionais) ${ }^{19}$; mercantilização, que acentua a lógica e a lei do mercado como chave principal das orientações e decisões estratégicas, e que tende a considerar o indivíduo/ destinatário mais como consumidor do que como cidadão (Traquina, 1993, p. 2) $)^{20}$.

18 Lange e van Loon (1991), cit. por Paquete de Oliveira, 1992, p. 1010.

19 Paquete de Oliveira, op. cit., p. 1022.

20 Nelson Traquina (1993): As indústrias culturais em Portugal: a alta indefinição no triângulo do audiovisual (comunicação apresentada no II Encuentro Iberoamericano de Investigadores de la Comunicación, Universidad Autónoma de Barcelona, 29 de Junho a 3 de Julho). 
O factor tecnológico é, neste contexto, de grande relevância. A convergência de sectores e de tecnologias (telecomunicações, informática e de media); a difusão galopante da distribuição de televisão e Internet por cabo; a expansão das redes digitais multimedia, constituem expressões de uma mudança profunda de incidência económica, política e sociocultural, cujos contornos e alcances não se encontram ainda claramente recortados.

Entendida como educação para a comunicação e para a cidadania, a educação para os media necessita, em Portugal e no contexto apresentado, de dar passos significativos a diversos níveis, que são decisivos para o seu desenvolvimento e consolidação, quer no âmbito da educação formal quer da não-formal.

Entre esses níveis, o mais decisivo continua a ser o da inovação nas práticas pedagógicas. É aí, na sala de aula, nas actividades extra-lectivas, no âmbito das associações (de alunos, de professores e outras), que projectos inovadores podem ser levados a cabo com imaginação e continuidade. Neste contexto, não se deve esquecer o papel que podem desempenhar as escolas e os colégios do ensino particular e cooperativo, os quais dispõem em muitos casos de uma flexibilidade e de uma margem de iniciativa que pode facilitar o desenvolvimento de projectos neste campo. Entretanto, e para não correr o risco da atomização e do permanente recomeço do ponto zero, torna-se necessário incentivar entre os agentes educativos envolvidos nas experiências no terreno 0 hábito do registo e reflexão crítica sobre as práticas de educação para os media, bem como da respectiva partilha, através de meios de comunicação existentes e a criar.

Neste mesmo sentido, é da maior importância continuar a investir na sensibilização dos centros de formação contínua de professores, tirando partido, por exemplo, de modalidades formativas menos convencionais como são os círculos de estudo, que tornam possível articular melhor a formação, a pesquisa e a acção. 0 que se diz da formação contínua deve dizer-se, por maioria de razão da formação inicial de professores e educadores, de animadores socioculturais, etc.

A investigação científica, designadamente realizada no âmbito de cursos de pós-gaduação com vista à obtenção de graus académicos, pode constituir um precioso instrumento de contextualização, enquadramento e fundamentação das experiências e projectos desenvolvidos. A qualidade dos cursos de pós-graduação pode beneficiar da exploração 
de oportunidades e programas de intercâmbio de docentes e estudantes, sobretudo no espaço ibero-americano.

De igual modo, também a avaliação constitui uma vertente fundamental da qualidade e eficácia da acção levada e a levar a cabo. Sendo certo que toda a investigação sobre problemas e aspectos do mundo empírico permite alguma forma de avaliação, esta não deixa de ter a sua lógica e metodologia próprias, que interessa desenvolver.

Não é, porém, suficiente atender às várias vertentes que podem concorrer para o desenvolvimento, expansão e qualificação da educação para os media. É também preciso ter em conta os modelos e paradigmas que fundamentam esta dimensão, cada vez mais considerada básica na formação dos cidadãos. Alguns tópicos que consideramos relevantes para essa reflexão são apresentados como contributos nos parágrafos seguintes:

1. Em primeiro lugar, parece-nos ser necessário prosseguir um trabalho de crítica aos modelos transferenciais e transmissivos, que continuam a predominar quer no âmbito educativo quer no comunicacional-mediático. A experimentação e teorização em torno de modelos e projectos mais interactivos e dialógicos que valorizem todos os parceiros do processo formativo, reveste um carácter determinante numa perspectiva de educação para a cidadania. Com efeito, do ponto de vista dos princípios orientadores da educação para os media, não deixa de ser uma contradição a aposta na formação de cidadãos críticos e participativos, tendo por base quadros e contextos comunicacionais marcados pela unidireccionalidade e pela desigualdade. É por isso que a educação para os media não se pode limitar ao uso dos media na escola. De certo modo, esse uso pode servir para reforçar ainda mais o modelo transferencial e transmissivo, porquanto o "decora» com o toque «modernista» ou "pós-modernista» dos media. "O problema não reside na infra-estrutura tecnológica, mas no projecto pedagógico, na concepção pedagógica e comunicacional que preside à introdução dos media na aula» (Kaplún, 1997)21.

21 Mario Kaplún (1997): «De medio y fines en comunicación», in Chasqui, Revista Latinoamericana de Comunicación, núm. 58. 
2. A procura de um novo paradigma, apoiado numa relação estreita entre a teoria e a prática, constitui uma via que muitos docentes vêm ensaiando, inspirados por pedagogos pioneiros como Freinet e Paulo Freire. Do nosso ponto de vista, trata-se de uma procura que exige abertura, persistência e determinação e que não está isenta de riscos, um dos quais é o da demagogia (também praticada por alguns media), que resulta de procurar dar aos alunos aquilo que eles gostam, de fazer o que eles querem, supondo que ser bom educador é ser um deles e não se assumir como adulto e como profissional. Essa procura terá de assentar num conhecimento aprofundado dos educandos, não apenas no seu papel de alunos, mas igualmente como pessoas, com os seus mundos, as suas relações, os seus grupos, as suas formas de expressão, as suas inquietações e problemas, as suas competências e os seus saberes. Do ponto de vista da educação para os media tal conhecimento parece-nos duplamente necessário, dado que as crianças e jovens são possuidores de uma experiência mediática de que não se pode prescindir nas iniciativas e projectos a levar a cabo.

3. Se a educação para os media for entendida como educação para a comunicação e para o exercício pleno da cidadania, então torna-se importante que o trabalho pedagógico esteja imbuído de um horizonte que transcenda e envolva o conjunto da vida social e política. E uma forma de promover essa consciência e essa capacidade de intervenção consiste em ser capaz de participar na mudança da própria vida escolar. Na verdade, não se compreenderia a promoção de projectos com o objectivo de promover a comunicação e de reflectir sobre as práticas comunicativas na sociedade em contextos escolares caracterizados pela incomunicação, pelo silêncio, quando não pela censura pura e simples. Pensamos, por isso, que uma das tarefas da educação para os media consiste em identificar as necessidades, potencialidades e bloqueamentos no plano da informação e da comunicação que se registam na escola (entre os alunos, entre os professores, entre a direcção e a comunidade escolar, entre os pais e a escola, entre a escola e a comunidade, entre a escola e os media locais, etc.), e encontrar meios e formas de mudar e melhorar a situação existente. 0 jornalismo escolar deveria ser entendido, neste contexto, como 
uma «escola» de aprendizagem da liberdade e da responsabilidade, que ajudasse a conhecer o que de significativo se passa ou vai passar, contribuísse para enunciar situações e problemas, e exprimir opiniões e desejos dos vários agentes educativos.

4. Por outro lado, torna-se necessário ancorar os projectos e as pesquisas no âmbito da educação para os media num conhecimento mais aprofundado dos quadros teórico-metodológicos historicamente desenvolvidos no campo multidisciplinar das Ciências da Comunicação. O confronto e diálogo com essas propostas teóricas permitirão situar melhor distintas orientações e ajuizar com mais acuidade das respectivas potencialidades e limites. Tornar-se-á, assim, mais saliente a concepção mediocêntrica predominante em muitos dos discursos e práticas de educação para os media. Um tal mediocentrismo, que, pelo menos como hipótese propomos como prevalecente, traz agarrada a si uma tendência para a descontextualização, quer ao nível dos media quer ao nível das práticas sociais de recepção-apropriação-significação. Ora para captar e iluminar o alcance destas várias dimensões do campo mediático e de assumir os media simultaneamente como resultado de uma produção simbólica no interior do sistema social e como agentes dessa mesma produção, torna-se necessária uma abordagem suportada em modelos mais complexos.

5. As tecnologias de informação e comunicação têm um papel importante na vida social e na escola. Em alguns contextos essa importância adquiriu uma expressão tal, que, como observávamos atrás, já não falta quem reduza a educação para os media ao ensino-aprendizagem do uso das tecnologias. Consideramos que é necessário, no actual quadro de sedução e de encantamento (ou, inversamente, de diabolização) da Internet e do multimedia, procurar os caminhos de uma abordagem crítica das tecnologias e de incorporar clara e decididamente a dimensão tecnológica no projecto da educação para os media. Tal objectivo - que é hoje quase decisivo para o futuro da cidadania e da educação - pressupõe a consciência de que a comunicação não se reduz à performatividade técnica, e que os progressos verificados nas tecnologias de informação e comunicação não acarretam automática e necessariamente progressos na comunicação. Mais do que 
se deixar embalar pelas fáceis e precipitadas contraposições e antinomias entre media novos e clássicos, importaria talvez indagar sobre os processos de recomposição e reconfiguração do panorama mediático, dos usos sociais dos media e das transformações nos modos e estilos de vida. Em suma, os novos media sugerem todo um itinerário de desafios, que, a nosso ver, a educação para os media não pode deixar de acolher e com os quais não pode deixar de dialogar.

\section{BIBLIOGRAFIA}

ABRANTES, José C. (1981): "Tecnologia educativa», in Manuela Silva e Isabel Támen (coord.), Sistema de Ensino em Portugal, Lisboa, Fundação Calouste Gulbenkian.

BALSEMÃo, Francisco P. (1992): O Pluralismo na comunicação social, Lisboa, Alta Autoridade para a Comunicação Social.

Downing, John; Mohammadi, A. e SREBerny-Mohammadi, A. (eds.) (1990): Questioning the Media: A Critical Introduction, Newbury Park-Londres-Nova Delhi, Sage.

GIDDEns, A. (1990): The Consequences of Modernity, Cambridge, Polity Press.

KAPLÚN, Mario (1997): «De medio y fines en comunicación», in Chasqui, Revista Latinoamericana de Comunicación, núm. 58.

MCQUAIL, Denis (1997): «Accountability of Media to Society: Principles and Means», in European Journal of Communication, vol. 12 (4), pp. 511-529.

MONTEIRO, Paulo Filipe (2000): «Uma margem no centro: a arte e o poder do 'novo cinema'», in Luís Reis Torgal (coord.): O cinema sob o olhar de Salazar, Lisboa, Círculo de Leitores, pp. 306-338.

PAQUETE DE OLIVEIRA, J. M. (1992): «A integração europeia e os meios de comunicação social», in Análise Social, vol. XXVII (4. ․-5. ${ }^{\circ}$, núm. 118-119, pp. 9951024.

PINTO, Manuel (2003): «Informação, conhecimento e cidadania a educação escolar como espaço de interrogação e de construção de sentido», in VV.AA.: Cruzamento de saberes, aprendizagens sustentáveis, Lisboa, Fundação Calouste Gulbenkian.

núm. 76, Novembro.

- (1997): «Objectivos e modelos de jornal escolar», in Público na Escola,

— (1991): «A imprensa na escola-guia do professor», Cadernos Público na Escola, núm. 1, Lisboa, Público Comunicação Social.

PINTO, Manuel e SANTOS, António (1995): «O cinema e a escola: guia do professor», Cadernos Público na Escola, núm. 6, Lisboa, Público Comunicação Social. 
Pinto, Manuel; Baleiras, Alda; SAntos, António e Pereira, Sara (1994): Escola e comunicação social: desafios e propostas de acção, Braga, CEFOPE da Universidade do Minho (polic.).

PONTE, João Pedro (2000): «Tecnologias de informação e comunicação na formação de professores: que desafios?», in Revista Ibero-americana de Educação, núm. 24, Setembro-Dezembro, OEI.

Postman, Neil (1994): Tecnopolia. Quando a cultura se rende à tecnologia, Lisboa, Difusão Cultural (edição original em inglês de 1992).

REIA-BAPTISTA, Vítor (1995): «Pedagogia da comunicação, cinema e ensino: dimensões pedagógicas do cinema», in Aguaded, Jose Ignacio (coord.): Educación y medios de comunicación en el contexto iberoamericano, Universidad Internacional de Andalucía, La Rábida, <http://bocc.ubi.pt/pag/_texto.php3?html2=reia-baptista-pedagogia-comunicacao.html>, [acedido em 20 de Maio de 2003].

SCANNELL, Paddy (1993): «Time, Space and Place in Broadcasting», in Katherin Skretting (ed.): Kringcasting og Kino, Oslo, Research Program for Culture and Tradition (KULT) series.

TEDESCO, Juan Carlos (s/d): La educación y las nuevas tecnologías de la información, IIPE/Buenos Aires, <http://www.orozco.cc/Educa/Docus/03tedesco3.htm>, [acedido em 5 de Junho de 2003].

TRAQUINA, Nelson (1993): As indústrias culturais em Portugal: a alta indefinição no triângulo do audiovisual (comunicação apresentada no II Encuentro Iberoamericano de Investigadores de la Comunicación), Universidad Autónoma de Barcelona.

VIEIRA, Ausenda e FonSECA, Teresa (1996): Os jornais escolares e o desenvolvimento de novas dinâmicas educativas, Lisboa, Instituto de Inovação Educacional.

VIEIRA, Ausenda e VARGAS, Rosália (1996): Rede de projectos de educação e media, Catálogo 1995-1996, Col. «Aprender com os Media», núm. 4, Lisboa, Instituto de Inovação Educacional.

WoLTON, Dominique (1999): Internet et après? Une théorie critique des nouveaux médias, París, Flammarion. 